\title{
The energy costs of walking on the level and on negative and positive slopes in the Granadina goat (Capra hircus)
}

\author{
BY M. LACHICA, THE LATE C. PRIETO AND J. F. AGUILERA* \\ Animal Nutrition Department, Estación Experimental del Zaidin (CSIC), Profesor Albareda, 1. \\ 18008 Granada, Spain
}

(Received 17 November 1995 - Revised 18 April 1996 - Accepted 18 May 1996)

\begin{abstract}
The energy expenditure of six goats averaging 35 (SE 0.3 ) $\mathrm{kg}$ was measured when the animals were standing or walking on a treadmill enclosed in a confinement-type respiration chamber at different speeds $(0.167,0.333$ and $0.500 \mathrm{~m} / \mathrm{s})$ and slopes $(-10,-5,0,+5$ and $+10 \%)$. The energy costs of locomotion, estimated from the coefficients of linear regressions of heat production (HP) per $\mathrm{kg}$ body weight $v$. distance travelled were $1.91,2.33,3.35,4.68$ and $6.44 \mathrm{~J} / \mathrm{kg} \mathrm{BW}$ per $\mathrm{m}$ for $-10,-5$, $0,+5$ and $+10 \%$ inclines respectively, indicating that the energy expenditure of walking over standing changes with slope according to a slightly curvilinear relationship. The energy cost of raising $1 \mathrm{~kg}$ body weight one vertical metre was found to be $31.7 \mathrm{~J}$, giving an average efficiency for upslope locomotion of $30.9 \%$. The energy recovered on vertical descent was estimated as $13.2 \mathrm{~J} / \mathrm{kg}$ per $\mathrm{m}$, indicating an efficiency of the energy recovered above the theoretical maximum.
\end{abstract}

Goat: Locomotion: Energy cost

The energy expenditure of locomotion contributes significantly to the energy requirement of animals in free-living conditions and must be included for accurate evaluation of the energy needs of the grazing animal. Past attempts to measure the energy expenditure of the animal at pasture have been reviewed by Whitelaw (1974) and Brockway (1978). In the main, data have been derived either from estimates of feed intake for constant live weight or by direct measurements on range. The usual and more reliable procedure for estimating free-living energy expenditure is the factorial method, whereby energy expenditure is calculated from calorimetric determination of the energy cost of various activities. Most of the increase in energy expenditure of physical activity results from grazing and locomotion costs, whereas the contribution of other activities is usually considered to be negligible. Although the energy cost of locomotion is relatively well defined in cattle (Ribeiro et al. 1977; Shibata et al. 1981; Lawrence \& Stibbards, 1990), sheep (Clapperton, 1964; Farrell et al. 1972; Brockway \& Boyne, 1980), equines (Yousef et al. 1972; Dijkman, 1992) and wild ungulates (Taylor et al. 1974; Brockway \& Gessaman, 1977; Cohen et al. 1978; White \& Yousef, 1978; Parker et al. 1984; Fancy \& White, 1985; Dailey \& Hobbs, 1989), no systematic studies, with the exception of the survey of Taylor et al. (1974), have been made with domestic goats. Published data suggest that there are interspecies differences in locomotory efficiency as a result of morphological, physiological and behavioural adaptations. Consequently, extrapolation of values derived from ruminant species other than the goat need further validation. While most of the studies have examined the energy cost of locomotion on the level, few studies have investigated the efficiencies associated with vertical ascent or descent. The present study was undertaken with the aim of determining the energy cost of 
walking on the level and on slopes in the Granadina goat (Capra hircus). A brief account of some preliminary results have been given elsewhere (Aguilera et al. 1991).

\section{MATERIALS AND METHODS}

\section{Animals}

Six adult female goats of the Granadina breed, of average body weights 29 (SE 0.2), 31 (SE 0.1), 34 (SE 0.6), 35 (SE 0.2), 39 (SE 0.1) and 42 (SE 0.3) kg were used. They were given lucerne (Medicago sativa) hay at about maintenance level. The estimated metabolizable energy content of the hay was 7.4 and $8.3 \mathrm{MJ} / \mathrm{kg} \mathrm{DM}$ in the first and second experiment respectively. The energy requirement for maintenance was taken as $401 \mathrm{~kJ} / \mathrm{kg}$ body weight $(\mathrm{BW})^{0.75}$ per d (Aguilera et al. 1990).

\section{Respiration chamber}

The heat production (HP) of each animal while standing at rest and while walking on a treadmill enclosed in a confinement-type respiration chamber (Lachica et al. 1995) was calculated from measurements of $\mathrm{CH}_{4}$ and $\mathrm{CO}_{2}$ production and $\mathrm{O}_{2}$ consumption (Brouwer, 1965). A confinement-type respiration chamber with fast response applications was used. The chamber was made of transparent acrylic plates and was provided with an internal ventilation system. When an animal was introduced into the chamber an aliquot sample of the air was continuously sucked from the chamber for analysis and then returned to the chamber. Before the $\mathrm{CO}_{2}$ level increased to about $1 \%$, the chamber was flushed out for a few minutes with a stream of fresh air. Shortly after the start and before the end of each confinement period the chamber air was sampled and its composition measured. The volume of the system multiplied by the concentrations of $\mathrm{CO}_{2}$ and $\mathrm{O}_{2}$ gave the volumes of these gases present at each measurement and, by difference, the amount produced and consumed. To calibrate the whole system pure $\mathrm{CO}_{2}$ and $\mathrm{O}_{2}$-free $\mathrm{N}_{2}$ were injected into the chamber from cylinders and the amounts of gases delivered determined gravimetrically. Over the course of the present experiments two calibrations per week were performed.

\section{Treadmill}

The treadmill (model BETA BRB/P, Beta Bellarosa, Ilario D'enza, Italy) had a belt which was supported on rollers and provided with a non-slipping surface $(1.32 \mathrm{~m}$ long by $0.48 \mathrm{~m}$ wide) made of rubber. It allowed selection of speeds and slopes in the range of $0-15 \mathrm{~km} / \mathrm{h}$ and -5 to $+15 \%$ respectively. The $-10 \%$ slope was achieved by raising the rear part of the treadmill with an appropriate wedge. No changes in the composition of the air of the chamber were detected when the treadmill belt was rolling at its highest speed in a preliminary blank test.

The tethering system for the goat consisted of a neck collar attached to the front panel of the treadmill by a short light chain. Each goat was repeatedly trained to walk on the treadmill. Full experimental adaptation was assumed when the animals walked in a steady way without dragging against their tethers.

\section{Experimental design}

Two experiments were performed. In the first, two replicate observations were made on each animal while standing at rest (speed $0 \mathrm{~m} / \mathrm{s}$ ) on each of five different slopes $(-10,-5$, 0,5 and $10 \%$ ), giving a total of sixty ( $\operatorname{six}$ animal $\times$ two replicate $\times$ five slope) 
determinations. This group of measurements was made to test the hypothesis of the existence of a postural effect on the goat's energy expenditure. In the second set of measurements, three replicate observations were made on each animal at each treatment combination of speed $(0.167,0.333$ and $0.500 \mathrm{~m} / \mathrm{s})$ and slope $(-10,-5,0,5$ and $10 \%)$, involving 270 (six animal $\times$ three replicate $\times$ three speed $\times$ five slope) determinations. The experimental treatments were arranged sequentially according to travel speed, so that each series of gas exchange measurements at a given speed was preceded by a measurement while the goat was standing still on the level (speed $0 \mathrm{~m} / \mathrm{s}$; slope, $0 \%$ ), therefore giving fifty-four (six animal $\times$ three replicate $\times$ three speed) additional measurements of the goats' energy expenditure.

The determinations began when the animals were well adapted to the experimental procedures and showed no signs of stress. The measurements of the energy expenditure took place $16-20 \mathrm{~h}$ after feeding. The goats were placed on the treadmill in the chamber at 09.00 hours. The experimental schedule consisted of $25-30 \mathrm{~min}$ standing followed by 20-25 min walking at each slope, the gas exchange being recorded after 5-10 min of adaptation of the animal to a new physical activity, to confirm that a steady state had been reached, and then for exactly $15 \mathrm{~min}$. The HP of the animal, calculated from the measured gas exchange, was referred to body weight and extrapolated to $1 \mathrm{~h}(\mathrm{~J} / \mathrm{kg} \mathrm{BW}$ per $\mathrm{h})$. The same pattern was repeated at each speed assayed. The length of the adaptation period was taken according to Shibata et al. (1981), who reported in heifers no significant differences in the energy expenditure of standing before and after 5-10 min walking at $0.5-1.0 \mathrm{~m} / \mathrm{s}$, a fact which indicates the lack of carry-over effects from preceding physical activities. They also found a significant decrease in $\mathrm{O}_{2}$ consumption during the first minute of exercise. Furthermore, Yoshida et al. (1959) obtained steady-state $\mathrm{O}_{2}$ consumption in cattle while pulling a load after 5 min of physical work.

The data from the first set of measurements were subjected to ANOVA (five treatments (slope) $\times$ six animals, with two replicates (calorimetry runs per animal)) following a twoway ANOVA with replication, with thirty degrees of freedom for within-animal error. The Bonferroni test was used to ascertain the statistical significance of differences in the energy cost of maintaining posture according to the slope assayed.

The energy costs of locomotion within slopes were estimated from the coefficient of linear regressions of $\mathrm{HP}(\mathrm{J} / \mathrm{kg} \mathrm{BW}$ per $\mathrm{h}) v$. distance travelled $\left(\mathrm{D}_{\mathrm{t}}, \mathrm{m}\right)$. For that purpose regression equations were obtained for each goat and the mean and standard error of the regression slopes were calculated ( $n$ 6). A one-way ANOVA analysis was made to assess differences between means.

The energy cost of vertical ascent and the energy recovered on vertical descent were calculated by multiple regression equations of $\mathrm{HP}(\mathrm{J} / \mathrm{kg} \mathrm{BW}$ per $\mathrm{h}) v$. distance travelled horizontally $\left(D_{h}, m\right)$ and vertically in ascent $\left(D_{u}, m\right)$ or descent $\left(D_{d}, m\right)$ respectively, using the following approach:

$$
\begin{aligned}
& D_{u}=\text { distance upward; equals } 0 \text { otherwise, } \\
& D_{d}=\text { distance downward; equals } 0 \text { otherwise. }
\end{aligned}
$$

Equations were fitted for each goat and estimates were then summarized over the six animals.

\section{RESULTS}

In the first experiment, carried out on goats standing still at each slope, eight determinations were discarded due to anomalous $R Q$ values which could not be attributed 
Table 1. The heat production (HP, J/kg body weight per $h$ ) and respiratory quotient (RQ) of goats (Capra hircus) walking on a treadmill belt at various speeds $(\mathrm{m} / \mathrm{s})$ and slopes (\%)

(Mean values with their standard errors)

\begin{tabular}{|c|c|c|c|c|c|c|c|}
\hline & \multicolumn{2}{|c|}{ Body wt (kg) } & \multicolumn{2}{|c|}{ HP } & \multicolumn{2}{|c|}{ RQ } & \multirow[b]{2}{*}{$n$} \\
\hline & Mean & $\mathrm{SE}$ & Mean & $\mathrm{SE}$ & Mean & $\mathrm{SE}$ & \\
\hline \multicolumn{8}{|l|}{ Speed } \\
\hline $0^{*}$ & $35 \cdot 3$ & 0.73 & 6960 & 177 & 0.89 & 0.016 & 52 \\
\hline $0 \cdot 167$ & 35.4 & 0.58 & $8988^{a}$ & 182 & $0.91^{\mathrm{a}}$ & 0.009 & 89 \\
\hline 0.333 & $35 \cdot 1$ & 0.51 & $11531^{b}$ & 308 & $0.85^{\mathrm{b}}$ & 0.010 & 86 \\
\hline 0.500 & 34.5 & 0.54 & $13835^{\mathrm{c}}$ & 392 & $0.84^{b}$ & 0.012 & 87 \\
\hline \multicolumn{8}{|l|}{ Slope } \\
\hline-10 & $34 \cdot 3$ & 0.65 & $9354^{\mathrm{a}}$ & 270 & $0.93^{\mathrm{a}}$ & 0.012 & 53 \\
\hline-5 & $35 \cdot 4$ & 0.73 & $9680^{\mathrm{ab}}$ & 278 & $0.85^{\mathrm{b}}$ & 0.016 & 51 \\
\hline 0 & $35 \cdot 0$ & 0.70 & $10914^{b}$ & 333 & $0.86^{\mathrm{b}}$ & 0.014 & 54 \\
\hline+5 & 34.9 & 0.73 & $12552^{c}$ & 444 & $0.85^{\mathrm{b}}$ & 0.013 & 53 \\
\hline+10 & 35.4 & 0.75 & $14732^{d}$ & 579 & $0.85^{\mathrm{b}}$ & 0.013 & 51 \\
\hline
\end{tabular}

a,b,c,d Mean values within a column not sharing a common superscript letter were significantly different $(P<0.05)$.

*Standing at rest on the level.

Table 2. The heat production (HP, J/kg body weight per h) of goats (Capra hircus) walking on a treadmill belt at various combinations of speed $(\mathrm{m} / \mathrm{s})$ and slope $(\%)$

(Mean values with their pooled standard error, for eighteen observations for each combination of speed and slope)

\begin{tabular}{|c|c|c|c|c|c|c|c|}
\hline & \multicolumn{6}{|c|}{ Slope } & \multirow[b]{2}{*}{ Pooled SE } \\
\hline & $0^{*}$ & -10 & -5 & 0 & 5 & 10 & \\
\hline \multicolumn{8}{|l|}{ Speed } \\
\hline 0.167 & 6660 & 8832 & 8306 & 8515 & 9404 & 10465 & 172 \\
\hline 0.333 & 7219 & 9103 & 9514 & 11329 & 12810 & 14718 & 174 \\
\hline 0.500 & 6987 & 10613 & 11289 & 12897 & 15613 & 19011 & 173 \\
\hline Pooled SE & 246 & 241 & 244 & 248 & 249 & 244 & \\
\hline
\end{tabular}

* Standing at rest on the level.

to either the calorimetric technique or the animal's behaviour. The energy expenditure of the goats was the same $(P>0.05)$ irrespective of the slope assayed. Average values for HP (n 6) were 6343(SE 221), 6367(SE 355), 6431(SE 242), 6047(SE 241) and 6471(SE 410) J/kg $\mathrm{BW}$ per $\mathrm{h}$, for $-10,-5,0,5$ and $10 \%$ slopes respectively, giving an overall mean value of 6332 (SE 67) J/kg BW per h (369(SE 3.9) $\mathrm{J} / \mathrm{kg}^{0.75}$ per d). An average value of 0.89 (SE 0.018) ( $n$ 52) for RQ was observed. As no postural effect on HP was detected, in the second set of experiments the energy expenditure of the goats while standing at rest was always measured with the treadmill belt horizontal.

In this second set of trials one animal showed signs of disease and was removed from the experiment until it achieved complete recovery. For that reason only 262 individual measurements of the energy expenditure of goats travelling on various gradients at different speeds, plus fifty-two additional HP determinations on animals standing at rest on the level, were performed. Tables 1 and 2 show the average results of the HP and RQ of goats walking at different speeds on the level and on positive and negative slopes. The factors 'speed' and 'slope' were highly significant $(P<0.001)$, as well as the interaction speed $\times$ slope $(P<0.05)$. The mean values of the energy cost of walking, estimated within 
Table 3. Average values (n 6) of the energy cost of walking ( $E C_{w}, J / k g B W$ per m) for goats (Capra hircus) estimated by individual regressions of heat production (HP, J/kg BW per $h$ ) v. distance travelled $\left(D_{t}, m\right)$

(Mean values with their standard errors)

\begin{tabular}{|c|c|c|c|c|c|c|c|c|c|c|}
\hline & \multicolumn{10}{|c|}{ Slope (\%) } \\
\hline & \multicolumn{2}{|c|}{-10} & \multicolumn{2}{|c|}{-5} & \multicolumn{2}{|c|}{0} & \multicolumn{2}{|c|}{+5} & \multicolumn{2}{|c|}{+10} \\
\hline & Mean & SE & Mean & SE & Mean & $\mathrm{SE}$ & Mean & SE & Mean & SE \\
\hline $\begin{array}{l}\mathrm{EC}_{\mathrm{w}} \\
\mathrm{HP} \text { at rest }\end{array}$ & $\begin{array}{l}1.91^{\mathrm{a}} \\
6960\end{array}$ & $\begin{array}{l}0 \cdot 129 \\
365\end{array}$ & $\begin{array}{l}2 \cdot 33^{\mathrm{a}} \\
6910\end{array}$ & $\begin{array}{l}0 \cdot 130 \\
366\end{array}$ & $\begin{array}{l}3 \cdot 35^{b} \\
6883\end{array}$ & $\begin{array}{l}0 \cdot 127 \\
342\end{array}$ & $\begin{array}{l}4.68^{c} \\
6841\end{array}$ & $\begin{array}{l}0.148 \\
333\end{array}$ & $\begin{array}{l}6.44^{d} \\
6838\end{array}$ & $\begin{array}{l}0.245 \\
329\end{array}$ \\
\hline
\end{tabular}

a,b,c,d Mean values within a row bearing unlike superscript letters were significantly different $(P<0.05)$.

slope from linear regression of HP (J/kg BW per h) $v$. distance travelled $\left(D_{t}, \mathrm{~m}\right)$ for each animal, appear in Table 3. The intercepts of the regression equations are estimates of the goats' metabolic rate while standing at rest $(\mathrm{J} / \mathrm{kg} \mathrm{BW}$ per $\mathrm{h})$. These were not statistically different and were similar to the mean value of 6960 (SE 177) $\mathrm{J} / \mathrm{kg} \mathrm{BW}$ per h (see Table 1) found in direct measurements of the goats while standing. This average value is equivalent to $405 \mathrm{~kJ} / \mathrm{kg}^{0.75}$ per $\mathrm{d}$. The mean RQ value for all observations was 0.87 (SE 0.0006$)$ ( $n$ 314). The mean slopes of these regression equations indicate that in the goat the energy cost of locomotion increases from 1.91 to $6.44 \mathrm{~J} / \mathrm{kg} \mathrm{BW}$ per m (or from 0.09 to $0.32 \mathrm{ml}$ $\mathrm{O}_{2} / \mathrm{kg} \mathrm{BW}$ per $\mathrm{m}$ ) on increasing the slope of the treadmill belt from -10 to $+10 \%$. From these estimates exponential relationships were derived which allow the calculation of the energy cost of locomotion $\left(\mathrm{EC}_{\mathrm{w}}, \mathrm{J} / \mathrm{kg} \mathrm{BW}\right.$ per $\mathrm{m}$ ) as a function of slope $(\mathrm{Sl}, \%)$ :

$$
\mathrm{EC}_{\mathrm{w}}=3.39(\mathrm{SE} 1.022) \mathrm{e}^{0.063(\mathrm{SE} 0.0031) \mathrm{Sl}}, r 0.996 \text {; residual SD 0.049; } n 5 .
$$

The mean values $(n 6)$ of the energy cost of walking, calculated for each goat by separation of the horizontal $\left(D_{h}\right)$ and vertical $\left(D_{u}\right.$ and $\left.D_{d}\right)$ components by multiple regression of $H P$ $(\mathrm{J} / \mathrm{kg} \mathrm{BW}$ per $\mathrm{h}) v$. the horizontal and vertical distances travelled $(\mathrm{m})$ in ascent or descent, were those given by the average equation:

$$
\mathrm{HP}=6724(\mathrm{SE} \mathrm{301})+3.31\left(\mathrm{SE} \mathrm{0.148)} \mathrm{D}_{\mathrm{h}}+31.7(\mathrm{SE} 1.59) \mathrm{D}_{\mathrm{u}}-13.2(\mathrm{SE} 1.33) \mathrm{D}_{\mathrm{d}}\right. \text {, }
$$

where the regression coefficents of $D_{h}, D_{u}$ and $D_{d}$ indicate values for the net energy cost $(\mathrm{J} / \mathrm{kg} \mathrm{BW}$ per $\mathrm{m})$ for horizontal $\left(\mathrm{EC}_{\mathrm{h}}\right)$ and vertical locomotion on ascent $\left(\mathrm{EC}_{\mathrm{u}}\right)$ and on descent $\left(\mathrm{EC}_{\mathrm{d}}\right)$ respectively.

The energy equivalent of the $\mathrm{O}_{2}$ consumed by the goats while walking, above that observed while standing at rest on the treadmill belt, was calculated by regressing the net energy expenditure due to locomotion ( $\left.\mathrm{HP}_{\text {walking }}-\mathrm{HP}_{\text {standing }}, \mathrm{J} / \mathrm{h}\right) v$. the increase in $\mathrm{O}_{2}$ consumption above standing $\left(\mathrm{O}_{2 \text { walking }}-\mathrm{O}_{2 \text { standing, }} \mathrm{ml} / \mathrm{h}\right)$ and was found to be $20 \cdot 3(\mathrm{SE}$ $0.03)(n$ 262).

\section{DISCUSSION}

The specific objectives of the present study were to assess the net energetic costs of horizontal and vertical locomotion of the Granadina goat by means of indirect calorimetry and to evaluate its additional energy expenditure due to physical activity in order to provide estimates of the overall energy expenditure of the grazing goat. The aim was to obtain more accurate estimations of its energy requirements on which to base patterns of management according to the availability of herbage. We are aware of the limitations of 
data derived from experiments with treadmills when extrapolating to free-living situations, particularly when the animal has to walk on soft, uneven or wet surfaces instead of on the firm, even surface of a treadmill (Fancy \& White, 1985). The experimental values assigned to the variables were selected to give rise only to moderate physical efforts, as is expected to happen in the grazing goat. During the present trials the animals travelled daily distances which ranged from 1500 to $4500 \mathrm{~m}$, while their metabolic rate was measured throughout $2.5 \mathrm{~h}$. Prieto et al. (1991) reported that goats grazing on semi-arid lands travelled, on average, daily distances of 3482-6432 $\mathrm{m}$ in autumn and summer respectively, depending on the seasonal availability of the pasture.

In the present study the speeds assayed were lower than those used in earlier trials (i.e. Taylor et al. 1974; Brockway \& Gessaman, 1977; Cohen et al. 1978; White \& Yousef, 1978; Boyne et al. 1981; Dailey \& Hobbs, 1989). The use of high speeds might improve the accuracy of the estimates of the locomotion costs, since in this case the energy expenditure of the animal while standing still is proportionately a minor fraction of total energy expenditure when exercising. However, the degrees of exercise and slope used in the present study did produce elevated HP up to 2.5 times that associated with rest.

Throughout the second set of experiments the goats kept a fairly constant body weight $(35.03$ (SE 0.29) kg) and their energy expenditure when standing at rest was close to 405 $\mathrm{kJ} / \mathrm{kg}^{0.75}$ per $\mathrm{d}$. These results suggest that the goats were well adapted to the experimental procedures, as previous results from this laboratory (Aguilera et al. 1990) indicate that the energy requirement for maintenance of the Granadina goat is $401 \mathrm{~kJ} / \mathrm{kg}^{0.75}$ per d. However, it should be pointed out that measurements were made 16-20 h after feeding. The energy expenditure over this period is unlikely to reflect accurately the mean daily heat production as many of the digestive, absorptive and metabolic processes will be 'post-peak'. Care needs to be exercised, therefore, in using the value obtained in the present experiment for comparative purposes.

We did not find statistical significance between the intercepts of the linear regression equations relating HP and distance travelled (Table 3), a fact which corroborates previous results from Brockway \& Gessaman (1977), suggesting that the energy cost of maintaining posture does not differ during walking and standing.

The net energy cost of locomotion, on the level, of a Granadina goat with an average body weight of $34.95 \mathrm{~kg}$ was $3.35 \mathrm{~J} / \mathrm{kg} \mathrm{BW}$ per $\mathrm{m}$, a value somewhat lower than that of $3.63 \mathrm{~J} / \mathrm{kg} \mathrm{BW}$ per $\mathrm{m}$ which can be calculated from data reported by Taylor $e$ t al. (1974) for another breed of domestic goat (Capra hircus), whereas it is close to that of $3.23 \mathrm{~J} / \mathrm{kg} \mathrm{BW}$ per $\mathrm{m}$, published by the same authors, for the desert gazelle (Gazella gazella). For other farm ruminant species the data lie well below the value found here. In sheep, Clapperton (1964), Farrell et al. (1972) and Brockway \& Boyne (1980) reported values of 2.47, 2.83 and $2.30 \mathrm{~J} / \mathrm{kg} \mathrm{BW}$ per $\mathrm{m}$ respectively; Ribeiro et al. (1977), Shibata et al. (1981) and Lawrence \& Stibbards (1990) obtained, in cattle, net energy expenditures of 2.09, 1.54 and $1.91 \mathrm{~J} / \mathrm{kg} \mathrm{BW}$ per $\mathrm{m}$ respectively. In wild ungulates, specifically in the mountain goat (Oreamnos americanus) and the bighorn sheep (Ovis canadensis), Dailey \& Hobbs (1989) calculated, from the slopes of linear regressions, net energy costs of horizontal locomotion which ranged from 0.24 to $0.28 \mathrm{ml} \mathrm{O}_{2} / \mathrm{kg} \mathrm{BW}$ per $\mathrm{m}$, with little variation between goats and sheep of similar body weight. When using our experimental value of $20.3 \mathrm{~J} / \mathrm{ml} \mathrm{O}$ the net energy cost of horizontal locomotion obtained in these trials was, on average, about $35 \%$ lower than the values reported in the American survey.

It is well documented that the energy cost of horizontal locomotion decreases with increasing body weight. However, the allometric equations proposed to estimate this cost as a function of body size (Taylor et al. 1970; Cohen et al. 1978) seem to be of 
questionable value because of interspecies differences in morphology, physiology and behaviour, causing great variations between predicted and observed locomotion costs.

It is generally recognised that the net energy cost of upslope locomotion is higher than that for moving on the level due to the energy expended to work against gravity, whereas during downslope travel potential energy is recovered as kinetic energy, leading to a decrease in energy expenditure relative to horizontal costs. Equation (1) states that the change in energy cost of locomotion with slope is slightly curvilinear.

The validity of the estimation of the energetic efficiency of locomotion by separation of the vertical and horizontal components (Stainsby et al. 1980), as made by equation (2) has been questioned, because with this method of calculation some work is done by raising the body's centre of gravity at each step, while travelling on the level is ascribed to the vertical component. Consequently, this procedure would overestimate the energy cost of vertical movement at the expense of the horizontal component. Our results seem to be free of this bias, as shown by comparing the estimate given by the mean slope of the linear regressions for locomotion on the level (Table 3) with the average coefficient of the horizontal component of the multiple regression equations mentioned above $(3 \cdot 35$ (SE $0.127) v 3.31($ SE 0.148)).

The net energy cost of lifting was calculated according to equation (2) at 31.7 (SE 1.59) $\mathrm{J} / \mathrm{kg} \mathrm{BW}$ per $\mathrm{m}(n \mathrm{6})$. The efficiency of upslope locomotion, calculated as the ratio of work done to the energy cost of doing it and expressed as a percentage, averaged $30.9 \%$. Published data for the energy cost of vertical locomotion are 25.4-27.0 (Clapperton, 1964), 32.0 (Farrell et al. 1972) and 27.7-37.7 J/kg BW per m (Brockway \& Boyne, 1980) for sheep; and 26.0 (Ribeiro et al. 1977) and 24.0-30.3 (Shibata et al. 1981) for cattle. From these costs apparent energetic efficiencies ranging from 40.9 to $26.0 \%$ can be calculated. The Agricultural Research Council (1980) gives a preferred value of $28 \mathrm{~J} / \mathrm{kg} \mathrm{BW}$ per $\mathrm{m}$ for the energy cost of the vertical movement for both sheep and cattle, equivalent to an energetic efficiency of $35 \%$.

The information available on the energy cost of downslope locomotion seems to be controversial. The Agricultural Research Council (1980) states that there is a lack of available data on this cost of descent in ruminant animals and thus assumes that it is similar to that of walking on the level. It is believed that downslope movements are less expensive because gravitational energy is recovered as kinetic energy during descent and it has also been reported (Fancy \& White, 1985) that the amount of potential energy recovered decreases with body weight and increasing angle of descent. It is doubtful whether this energy can be recovered by the body. The term 'negative work' although unacceptable according to thermodynamic laws, has been extensively used by physiologists to define the work done in activities such as lowering a weight or going downhill, when antagonist muscles lengthen under tension while others shorten. Data on the energy recovered during downslope locomotion are extremely variable (18.2-19.9, Margaria et al. 1963; 5.8-7.0, White \& Yousef, 1978; 2.8-7.4, Parker et al. 1984; - 0.2-0.2, Dailey \& Hobbs, 1989; and $2.0-4.2 \mathrm{~J} / \mathrm{kg} \mathrm{BW}$ per $\mathrm{m}$, Dijkman, 1992). We observed that the average amount of energy recovered when moving downslope, calculated by equation (2), was $13 \cdot 2(\mathrm{SE} 1 \cdot 33$ ) J/kg BW per $\mathrm{m}(n 6)$. The energetic efficiency of this activity, calculated as the energy recovered: energy stored ratio and expressed as a percentage, was found to be $134.6 \%$. Our results indicate that, as reported by other authors (Margaria et al. 1963 and Boyne et al. 1981, in human subjects; Raab et al. 1976, in dogs), the amount of energy recovered during downslope locomotion exceeds the maximum transfer in potential energy per metre vertical movement, being impossible to conceive a satisfactory explanation in terms of saving of negative work. As stated by G. Cavagna (personal communication), efficiency in 
a physical sense can only be measured during positive work, but not during negative work when both chemical and mechanical energies enter the muscle and nothing is produced except heat. Similarly, K.L. Parker (personal communication) points out that the classic method of calculation of efficiency, based on the recovery of potential energy, is meaningless. Consequently, we think that the coefficient of the vertical component $\left(D_{d}\right)$ in the regression equation (2) is only an index of the likely energy-saving effect of negative work and has no other meaning, such as the recovery of gravitational potential energy.

The authors wish to thank Dr L. Lara for statistical help. This work was supported by LUCDEME Program (CSIC-ICONA).

\section{REFERENCES}

Agricultural Research Council (1980). The Nutrient Requirements of Ruminant Livestock. Slough: Commonwealth Agricultural Bureaux.

Aguilera, J. F., Lachica, M. \& Prieto, C. (1991). Energy cost of locomotion in Granadina goats. In Energy Metabolism of Farm Animals, European Association for Animal Production Publication no. 58, pp. 425-428 [C. Wenk and M. Boessinger, editors]. Zürich: Institut für Nutztierwissenschaften.

Aguilera, J. F., Prieto, C. \& Fonollá, J. (1990). Protein and energy metabolism of lactating Granadina goats. British Journal of Nutrition 63, 165-175.

Boyne, A. W., Brockway, J. M., Ingram, J. F. \& Williams, K. (1981). Modification, by tractive loading, of the energy cost of working in sheep, cattle and man. Journal of Physiology 315, 303-316.

Brockway, J. M. (1978). Escape from the chamber: alternative methods for large animal calorimetry. Proceedings of the Nurtrition Society 37, 13-19.

Brockway, J. M. \& Boyne, A. W. (1980). The energy cost for sheep of walking on gradients. In Energy Metabolism of Farm Animals, European Association for Animal Production Publication no. 26, pp. 449-453 [L. E. Mount, editor]. London: Butterworths.

Brockway, J. M. \& Gessaman, J. A. (1977). The energy cost of locomotion on the level and on gradients for the red deer (Cervus elaphus). Quarterly Journal of Experimental Physiology 62, 333-339.

Brouwer, E. (1965). Report of Sub-committee on Constants and Factors. In Energy Metabolism of Farm Animals, European Association for Animal Production Publication no. 11, pp. $441-443$ [K. L. Blaxter, editor]. London: Academic Press.

Clapperton, J. L. (1964). The energy metabolism of sheep walking on the level and on gradients. British Journal of Nutrition 18, 47-54.

Cohen, Y., Robbins, C. T. \& Davitt, B. B. (1978). Oxygen utilization by elk calves during horizontal and vertical locomotion compared to other species. Comparative Biochemistry and Physiology 61 A, 43-48.

Dailey, T. V. \& Hobbs, N. T. (1989). Travel in alpine terrain: energy expenditures for locomotion by mountain goats and bighorn sheep. Canadian Journal of Zoology 67, 2368-2375.

Dijkman, J. T. (1992). A note on the influence of negative gradients on the energy expenditure of donkeys walking, carrying and pulling loads. Animal Production 54, 153-156.

Fancy, S. G. \& White, R. G. (1985). Incremental cost of activity. In Bioenergetics of Wild Herbivores, pp. 143160 [R. J. Hudson and R. G. White, editors]. Boca Raton: CRC Press.

Farrell, D. J., Leng, R. A. \& Corbett, J. L. (1972). Undernutrition in grazing sheep. II. Calorimetric measurements on sheep taken from pasture. Australian Journal of Agricultural Research 23, 466-509.

Lachica, M., Aguilera, J. F. \& Prieto, C. (1995). A confinement respiration chamber for short gaseous exchange measurements. Archives of Animal Nutrition 48, 329-336.

Lawrence, P. R. \& Stibbards, R. J. (1990). The energy cost of walking, carrying and pulling loads on flat surfaces by Brahman cattle and swamp buffalo. Animal Production 50, 29-39.

Margaria, R., Cerretelli, R., Aghemo, P. \& Sassi, G. (1963). Energy cost of running. Journal of Applied Physiology 18, 367-370.

Parker, K. L., Robbins, C. T. \& Hanley, T. A. (1984). Energy expenditures for locomotion by mule deer and elk. Journal of Wildlife Management 48, $474-488$.

Prieto, C., Lachica, M., García-Barroso, F., Aguilera, J. F. \& Boza, J. (1991). The effect of seasonal variation in grazing activities on the energy requirements of goats. FAO Network of Cooperative Research on Sheep and Goats. Proceedings of the Meeting of the Subnetwork Nutrition, pp. $20-21$ [J. E. Lindberg, editor]. Östersund: Sveriges Lantbruksuniversitet.

Raab, J. L., Eng, P. \& Waschler, R. A. (1976). Metabolic cost of grade running in dogs. Journal of Applied Physiology 41, 532-535. 
Ribeiro, J. M. De C. R., Brockway, J. M. \& Webster, A. J. F. (1977). A note on the energy cost of walking in cattle. Animal Production 25, 107-110.

Shibata, M., Mukai, A. \& Kume, S. (1981). Estimation of energy expenditure in dairy heifers walking on the level and on gradients. Bulletin of the Kyushu National Agricultural Experiment Station 21, 589-607.

Stainsby, W. N., Gladden, L. B., Barclay, J. K. \& Wilson, B. A. (1980). Exercise efficiency: validity of base-line subtractions. Journal of Applied Physiology 48, 518-522.

Taylor, C. R., Schmidt-Nielsen, K. \& Raab, J. L. (1970). Scaling of energetic cost of running to body size in mammals. American Journal of Physiology 291, 1104-1107.

Taylor, C. R., Shkolnik, A., Dmi'el, R., Baharav, D. \& Borut, A. (1974). Running in cheetahs, gazelles and goats: energy cost and limb configuration. American Journal of Physiology 227, 848-850.

White, R. G. \& Yousef, M. K. (1978). Energy expenditure in reindeer walking on roads and on tundra. Canadian Journal of Zoology 56, 215-223.

Whitelaw, F. G. (1974). Measurement of energy expenditure in the grazing ruminant. Proceedings of the Nutrition Society 33, 163-172.

Yoshida, T., Notsuki, I. \& Okubo, T. (1959). Studies on the energy metabolism in Japanese breed of cattle. II Energy metabolism during pulling work, especially on relations of speed and load to energy metabolism. Bulletin of the Chyugoku National Agricultural Experiment Station, Series B 4, 75-92.

Yousef, M. K., Dill, D. B. \& Freeland, D. V. (1972). Energy cost of grade walking in man and burro, Equus asinus: desert and mountain. Journal of Applied Physiology 53, 337-340. 


\section{An overview of} international nutritional research in one publication.....

\section{Nutrition} Research Reviews

\author{
General Editor \\ MI Gurr (UK) \\ Editors \\ JWT Dickerson (UK) \\ JM Forbes (UK) \\ D J Millward (UK) \\ DI Thurnham (UK) \\ International Editors \\ LH Allen (USA) \\ J Black (Australia) \\ LHambraeus (Sweden) \\ JOkumura (Japan) \\ NW Solomons (Guatemala)
}

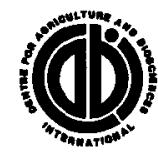

CAB INTERNATIONAL
This leading journal, published annually, presents authoritative, critical, in-depth review articles by international experts that:

- advance new concepts

- encourage fresh thinking on nutritional problems

- report on the most important techniques and methods in experimental work

- provide overviews on specific subject areas from internationallyrenowned nutritionists

Reviews of large-scale, international projects and surveys also feature within this not-to-be-missed publication.

Key topics due to be covered in 1997:

- Eradicating vitamin A deficiency in developing countries

- Role of modelling in understanding metabolism

- Breast feeding and maternal health

- n-3 fatty acids in growth and development

- Cardiovascular risk in developing countries: paediatric lipid profiles

1997, Volume 10

Annual Publication (December)

ISSN: 09544224

$£ 60.00$ (US $\$ 110.00$ Americas only)

To order your 1997 copy of this important information contact: CAB INTERNATIONAL

Wallingford, Oxon, OX10 8DE, UK

Tel: +44 (0) 1491832111

Fax: +44 (0) 1491826090

E-mail:marketing@cabi.org

CAB INTERNATIONAL

198 Madison Avenue,

New York, NY10016, USA

Tel: +1 (212) 7266490

or +1 (212) 7266491

Toll-free: 18005284841

Fax: +1 (212) 6867993

E-mail:cabi-nao@cabi.org 